\title{
6 Reibung
}

\subsection{Coulombsches Reibgesetz}

\section{Basismodell mit einheitlichem Reibkoeffizienten}

Kontaktkräfte erfüllen die Betragsungleichung:

$$
|R| \leq \mu N
$$

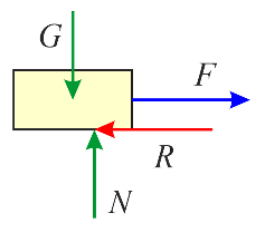

\section{Unterscheidung in Haft- und Gleitreibkoeffizient}

Experimentelle Ermittlung:
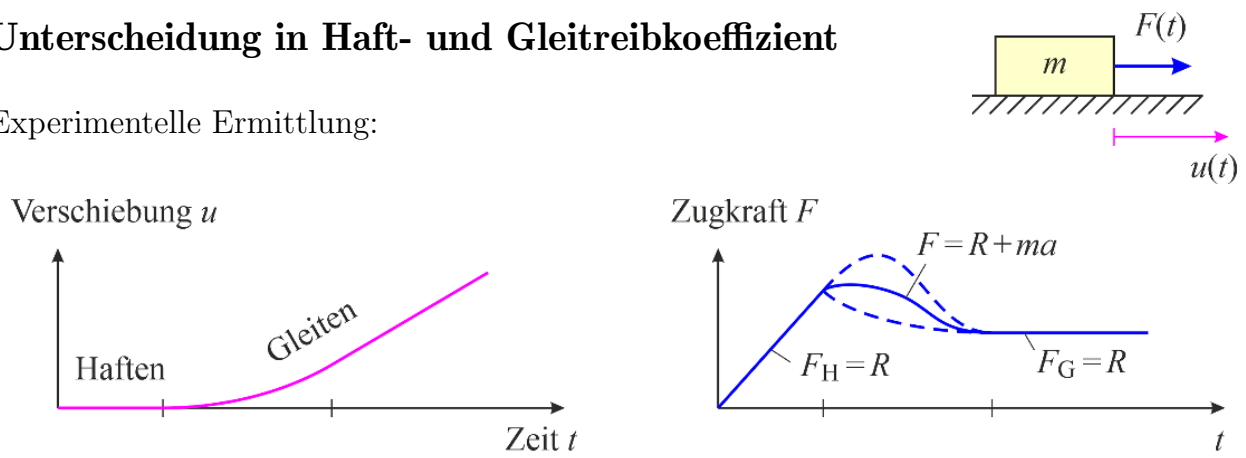

Zugkraft $F$
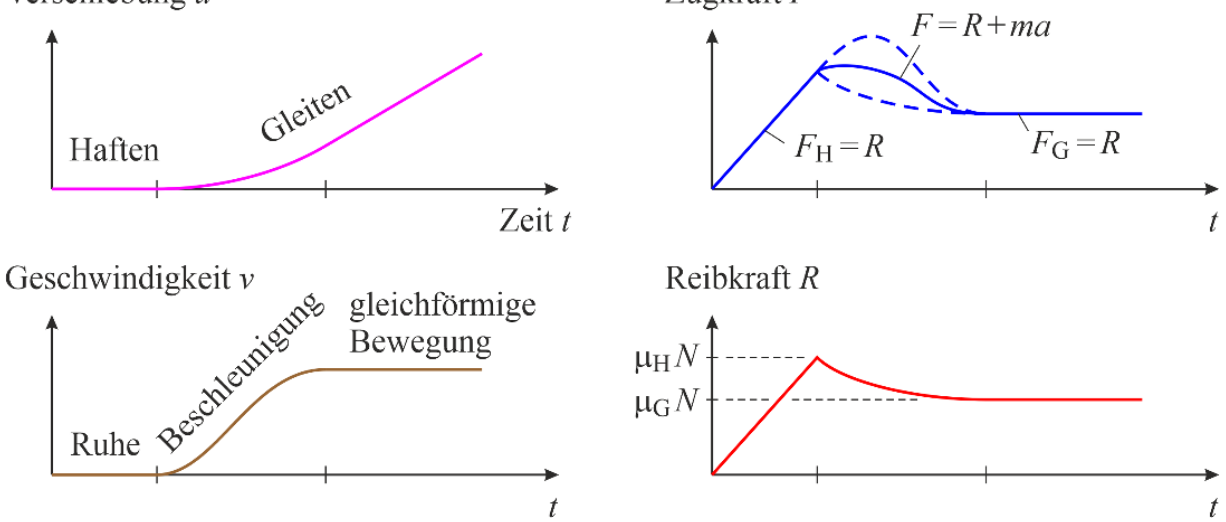

Reibkraft $R$

\subsection{Seilreibung}

\section{Euler-Eytelwein-Formel}

Für die Seilkräfte $S_{1}$ und $S_{2}$ gilt:

$$
\mathrm{e}^{-\mu \alpha} \leq \frac{S_{1}}{S_{2}} \leq \mathrm{e}^{+\mu \alpha}
$$

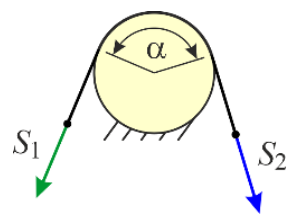

Der Umschlingungswinkel $\alpha$ muss in Bogenmaß angegeben werden. 